Research Article

www.jestr.org

\title{
Analysis of SMA Actuated Plain Flap Wing
}

\author{
M. Senthilkumar* \\ Dept. of Mechanical Engineering, PSG College of Technology, Coimbatore 641 004, India
}

Received 21 July 2011; Revised 9 February 2011; Accepted 15 July 2012

\begin{abstract}
In the past few decades, developments in smart materials have shown the promise of providing better actuation systems to improve aerodynamic performance of the wing. When properly trained, shape memory alloy (SMA) wires act as linear actuators by contracting when heated. In this paper, these SMA wire actuators are used to deflect the plain flap and control the flap angle of aircraft wing. The aerodynamic characteristics of SMA actuated plain flap aerofoil structures are investigated. The results of experimental studies on the lift force acting on the aerofoil structure at specific air velocity and angle of attack are investigated and presented. It is found that the SMA wire is an effective actuator in smart wings.
\end{abstract}

Keywords: Plain Flap, SMA, Lift force, Wind Tunnel.

\section{Introduction}

A small percentage reduction in the fuel consumption of an airplane can lead to major savings in aircraft operational costs. Since the amount of fuel stored in the aircraft is limited, lower fuel consumption means greater range or endurance in flight. There has been a great deal of research focused on achieving this goal. On modern aircraft, a large number of aerodynamic devices, such as slats, slots, flaps, spoilers, and dive brakes, affixed to a simple wing serve to increase or decrease lift and drag.

The advantages of smart composites in shape control applications are well explored by Merja Sippola, Umesh, and $\mathrm{Yan} \mathrm{Ru} \mathrm{Hu}$ [1-3]. Static and dynamic shape control of structures by piezoelectric actuation is reviewed by Irschik [4]. Use of shape memeory alloy actuators in smart structures has been explored by Seelecke and Muller [5]. The shape control of composites beam with SMA wires is investigated by Sup Choi [6]. Kevin O'Toole [7] has evaluated the performance of SMA actuator for prosthetic hand. Multi-element high lift systems for transport airplanes have been aerodynamically designed by Van Dam [8]. Bioinspired wing design has been proposed by MacArthur [9]. Recent research in smart materials shows their potential for changing the configuration of airplane wing to improve aerodynamic performance and shows that they can eliminate the complexity and bulkiness of the actuating systems that are used in conventional wings [10]. A reconfigurable wing has been modeled by Justin [11]. The general idea of changing the wing configuration for this concept is to induce strain in the structure by interfacing with smart materials. The challenges of shape morphing of aircraft wings have been explored by Sofla et al. [12]. For SMAs, the deformation is a result of phase transformation of material

\footnotetext{
*E-mail address:msenthil_kumar@hotmail.com

ISSN: 1791-2377 @ 2012 Kavala Institute of Technology. All rights reserved.
}

due to temperature change caused by electric field. The SMA changes its shape upon heating process and returns to its original shape upon cooling [13]. In this paper, wings with plain flap were actuated by using SMA wires. The performances of these wings were determined at a specific air velocity and various angles of attack.

\section{Working Principle}

SMA possesses an interesting property by which the metal "remembers" its original size or shape and reverts to it at a characteristic transformation temperature. These alloys change phase (between matensite and austenite) at certain critical temperatures and therefore they display different stress-strain characteristics in different temperature ranges. Numerical simulation of double SMA wire actuator has been carried out by Kim and Cho [14]. The thermomechanical behavior of Nitinol wires with high strain stares has been analyzed by Vitiello et.al. [15]. An SMA wire is put through a temperature cycle as shown in Figure 1. The critical temperatures are $\mathrm{M}_{\mathrm{s}}, \mathrm{M}_{\mathrm{f}}, \mathrm{A}_{\mathrm{s}}$, and $\mathrm{A}_{\mathrm{f}}$ with the martensite fraction changing from $\xi=0$ to $\xi=1$ where $\mathrm{M}$ is martensite, A is austenite, $\mathrm{s}$ is start and $\mathrm{f}$ is finish. It may be noted that in the above temperature cycle, no mechanical stress was applied. The cycle is completely driven by temperature. Structural fatigue of pseudoelastic NiTi shape memory wires has been found out by Wagner et al. [16].

The electrical and mechanical properties of SMA (nitinol) wire (purchased from $\mathrm{m} / \mathrm{s}$. Dynalloy.inc) are shown in Table 1 , from which it can be inferred that as the wire diameter increases, the pull force gets increased. But the current required to heat and time required for cooling also increase considerably. Figure 2 shows the working principle of the model with plain flap. Once the SMA wire is actuated, it contracts and pulls the flap downwards. The extent of flap movement is controlled by the intensity of the electrical 
power passed through the SMA wire. Once the actuation of the SMA wire is stopped, the SMA wire cools by natural convection and returns to its original length and the spring pulls the flap to its initial position.

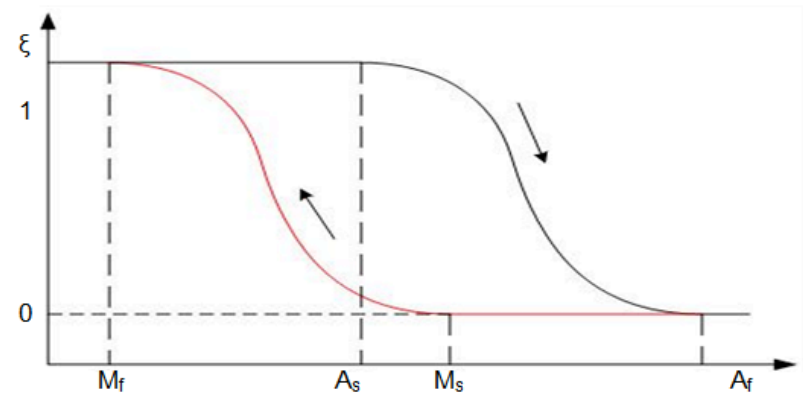

Fig. 1. Martensite fraction in an SMA wire at critical temperatures

Table 1. Properties of SMA wire (nitinol)

\begin{tabular}{crc}
\hline $\begin{array}{c}\text { Diameter } \\
\text { Size (mm) }\end{array}$ & $\begin{array}{c}\text { Pull } \\
\text { Force (N) }\end{array}$ & $\begin{array}{c}\text { Approximate Current at } \\
\text { Room Temperature (mA) }\end{array}$ \\
\hline 0.025 & 9.07 & 45 \\
0.038 & 20.38 & 55 \\
0.050 & 36.29 & 85 \\
0.076 & 81.75 & 150 \\
0.102 & 145.26 & 200 \\
0.127 & 227.00 & 320 \\
0.152 & 326.81 & 410 \\
0.203 & 581.00 & 660 \\
0.254 & 907.85 & 1050 \\
0.305 & 1307.34 & 1500 \\
0.381 & 2042.71 & 2250 \\
0.508 & 3631.60 & 4000 \\
\hline
\end{tabular}

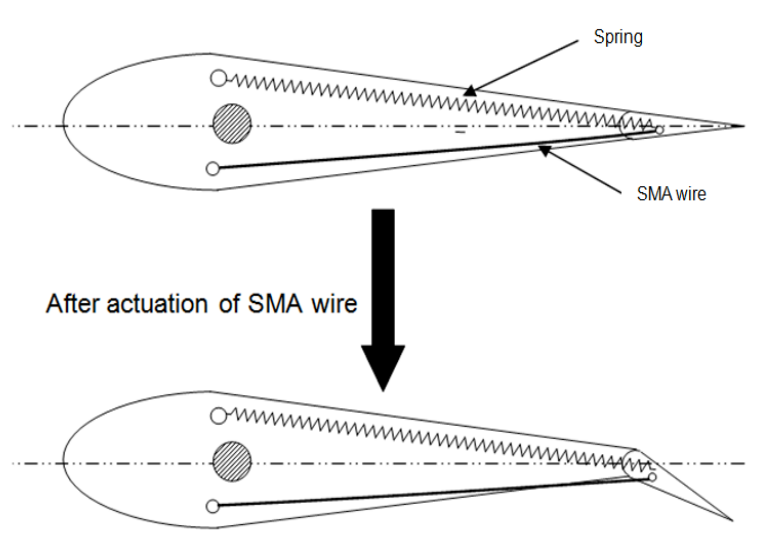

Fig. 2. Working principle of plain flap aerofoil structure with SMA

The force due to impact of air flow on the flap was calculated to determine the number of SMA wires to be used. The schematic representation of the impact of jet of air on the flap is shown in Figure 3.

Mass of the air per sec striking the plate,

$\mathrm{m}_{\mathrm{a}}=\rho \cdot a \cdot v \sin \theta, \mathrm{kg}$ where $\mathrm{v}$ is the velocity of the jet in the direction of $\mathrm{x}, \mathrm{m} / \mathrm{s}, \theta$ is the angle between the jet and the plate, degree, $a$ is area of cross section of jet hitting the plate, $\mathrm{m}^{2}$, and $\rho$ is the density of air, $\mathrm{kg} / \mathrm{m}^{3}$.I $\mathrm{f}$ the plate is smooth and if it is assumed that there is no loss of energy due to impact of jet, then jet will move over the plate after striking with a velocity equal to initial velocity, i.e. with a velocity $\mathrm{v}$.

Then, the force exerted by the jet on the plate in the direction normal to plate, $F_{n}$,

$$
F_{n}=\rho \cdot a \cdot v^{2} \cdot \sin ^{2} \theta, \mathrm{N}
$$

The force can be resolved in two components, one in the direction of jet and other perpendicular to the jet.

$$
F_{x}=\rho \cdot a \cdot v^{2} \cdot \sin ^{3} \theta, N
$$

and

$$
F_{y}=\rho \cdot a \cdot v^{2} \cdot \sin \theta \cdot \cos \theta, N
$$

Table 2 \& 3 show the variation of force on flap according to flap angle at wind velocities of $30 \mathrm{~m} / \mathrm{s}$ and 15 $\mathrm{m} / \mathrm{s}$ respectively. The SMA wires generating only horizontal force is considered to find the number of SMA wires needed. From the force requirement, it is found that two sets of three SMA wires (diameter $0.102 \mathrm{~mm}$ ) needed to be actuated alternatively in order to deflect the flap. In order to control the current to keep temperature at desired value, sophisticated controllers are required. However, here in this work, the switching circuit was used to actuate the two sets of SMA wire alternatively.

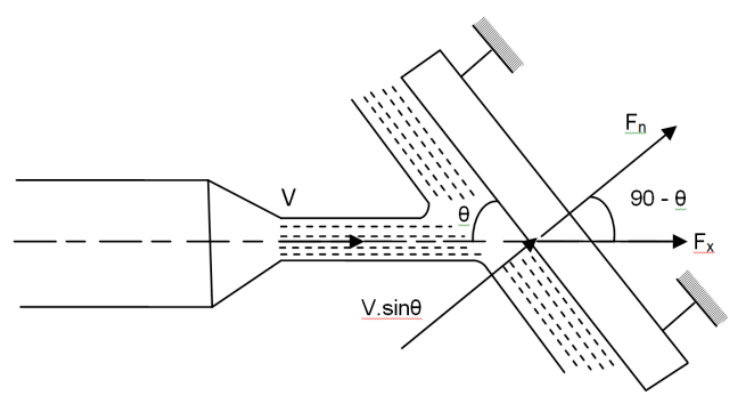

Fig. 3. Schematic diagram of impact of jet on flap

Table 2. Variation of force on flap according to flap angle at $30 \mathrm{~m} / \mathrm{s}$

\begin{tabular}{llll}
\hline Angle of flap $\left(^{\circ}\right)$ & $\mathbf{F}_{\mathbf{x}}(\mathbf{N})$ & $\mathbf{F}_{\mathbf{y}}(\mathbf{N})$ & $\mathbf{F}_{\mathbf{n}}(\mathbf{N})$ \\
\hline 0 & 0 & 0 & 0 \\
5 & $2.41 * 10^{-3}$ & 0.027 & 0.028 \\
10 & 0.019 & 0.108 & 0.11 \\
15 & 0.063 & 0.236 & 0.244 \\
20 & 0.146 & 0.401 & 0.427 \\
25 & 0.275 & 0.59 & 0.651 \\
30 & 0.456 & 0.79 & 0.912 \\
35 & 0.689 & 0.983 & 1.2 \\
40 & 0.969 & 1.155 & 1.5 \\
\hline
\end{tabular}

Table 3. Variation of force on flap according to flap angle at $15 \mathrm{~m} / \mathrm{s}$ 


\begin{tabular}{cccc}
\hline Angle of flap $\left(^{\circ}\right)$ & $\mathbf{F}_{\mathbf{x}}(\mathbf{N})$ & $\mathbf{F}_{\mathbf{y}}(\mathbf{N})$ & $\mathbf{F}_{\mathbf{n}}(\mathbf{N})$ \\
\hline 0 & 0 & 0 & 0 \\
5 & $3.04^{*} 10^{-3}$ & 0.0348 & 0.0349 \\
10 & 0.0241 & 0.1367 & 0.1388 \\
15 & 0.0798 & 0.297 & 0.3075 \\
20 & 0.184 & 0.5060 & 0.5384 \\
25 & 0.347 & 0.745 & 0.821 \\
30 & 0.575 & 0.997 & 1.15 \\
\hline
\end{tabular}

\section{Experimentation}

\subsection{Plain flap wing}

A model of the SMA controlled wing (NACA 0012 aerofoil) [17] with plain flap was fabricated from balsa wood as shown in Figure 4. The chord length of the model is $220 \mathrm{~mm}$ and the span is $210 \mathrm{~mm}$. Six SMA wires of diameter $0.102 \mathrm{~mm}$ were used in the model. The flap dimension is $15 \mathrm{~mm}$ width and $210 \mathrm{~mm}$ span. A small groove is cut along the span of the flap in order to accommodate the common ground wire. Each SMA wire is crimped to an electrical wire which is in turn soldered to the common ground which is fixed to the flap as shown in Figure 5. The other end of the SMA wires is fixed on to the aerofoil structure with the help of crimps. With the help of an electrical switching circuit, current is passed alternatively through the two positive potential wires and the common negative potential wire in order to actuate three SMA wires at a time. The flap was hinged on the aerofoil structure. An 8 $\mathrm{mm}$ rod is passed through the model and $8 \mathrm{~mm}$ bolt is welded on both sides in order to mount the model in the wind tunnel. The Figure 6 shows the completed wind tunnel model of the SMA controlled aerofoil structure with flap.

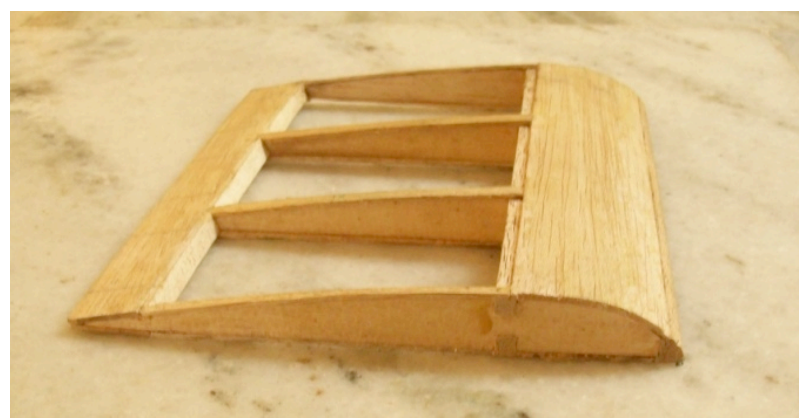

Fig. 4. Aerofoil structure fabricated from balsa wood

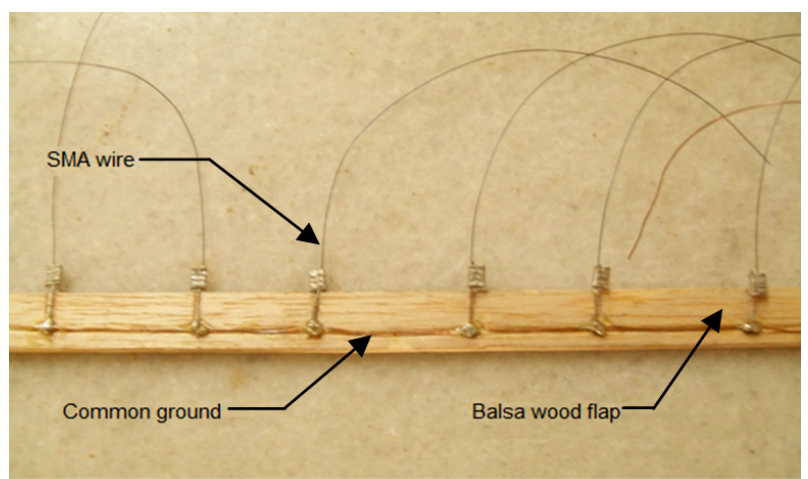

Fig. 5. SMA wire fixed on the flap

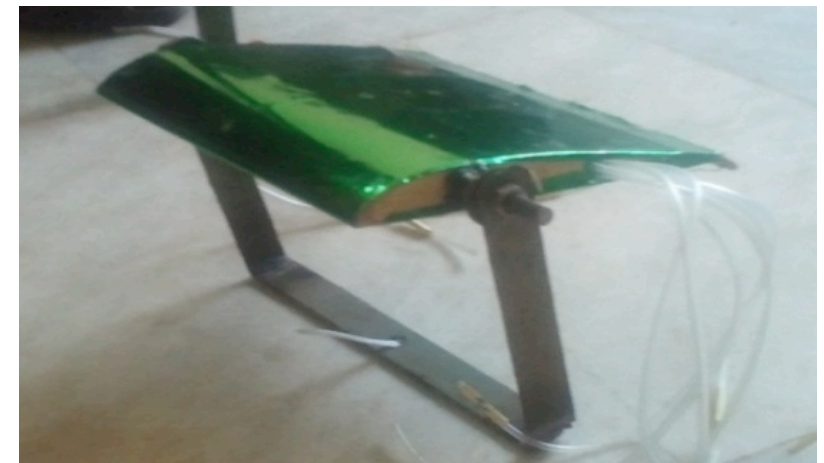

Fig. 6. Completed model of the SMA controlled aerofoil structure with flap

\subsection{Wind Tunnel and SMA actuation}

Figure 7 shows the low speed wind tunnel equipment with a test section area of $300 \mathrm{~mm} \times 300 \mathrm{~mm}$ in which the model was tested. Though the maximum wind velocity inside the wind tunnel is $30 \mathrm{~m} / \mathrm{s}$, the model was tested at a wind speed of $15 \mathrm{~m} / \mathrm{s}$. The wind tunnel has strain gauge to measure lift/drag with digital display and multi-tube manometer bank (12 nos) to measure the pressure at various points.

Since the SMA wire loses its property if continuously heated for a long time, the wire was intermittently heated. Cooling of the wire was due to natural convection. A switching circuit was designed to actuate two sets of SMA wire alternatively. The timing of actuation can be varied according to the SMA wire diameter through a simple program. A schematic of the circuit is shown in Figure 8.

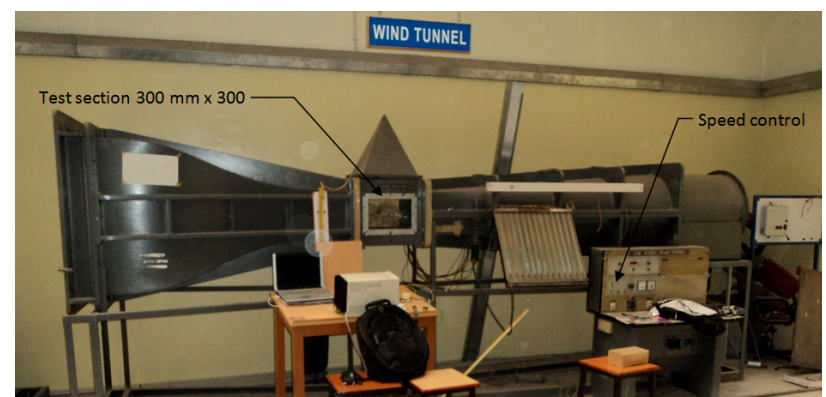

Fig. 7. Low speed wind tunnel

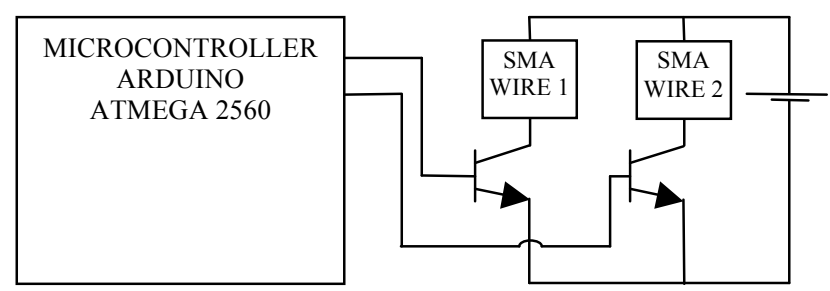

Fig.8 Schematic diagram of the switching circuit

\section{Results and Discussions}

The theoretical analysis was conducted using software, DesignFOIL. Figure 9 shows the results of the plain flap structure from theoretical analysis using DesignFOIL. Preliminary tests were conducted in order to find the relationship between the power required to actuate the SMA wire and the angle of flap deflected. The voltage was kept constant at $1 \mathrm{~V}$ and the current was increased to deflect the flap. The current consumed at various flap angles was noted. 
Figure 10 shows the variation of the current with increase in flap angle. The current consumption was found to be more or less linear over the range of $(0-20)^{\circ}$ of flap angle. Hence the flap angle can be controlled by SMA wire within this linear range. At higher flap angle, the force generated by the SMA wire increases so does the current consumption also.

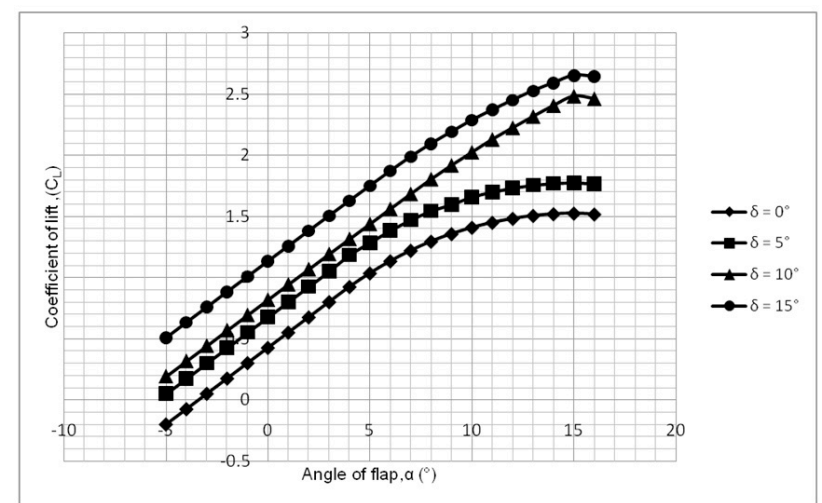

Fig. 9. Results of the plain flap structure from theoretical analysis using DesignFOIL

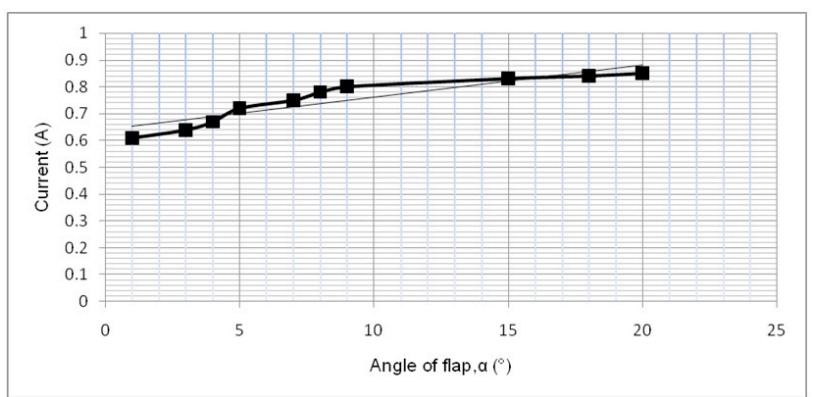

Fig. 10. Variation of current consumption with respect to flap angle

The wind tunnel testing of the model was conducted at wind velocity $15 \mathrm{~m} / \mathrm{s}$. The wing mounted on the steel bracket was fixed on the lift sensor inside the wind tunnel. The angle of attack was kept constant and the SMA wire was actuated to deflect the flap through various angles and the corresponding lift was measured. Figure 11 shows the experimental variation of coefficient of lift with angle of attack. The stall angle is found to be around $16^{\circ}$. The decrease in coefficient of lift after the stall angle is due to the separation of boundary layer in the flow. Since the aerofoil profile is non-symmetric, lift was generated at $0^{\circ}$ flap angle and $0^{\circ}$ angle of attack.

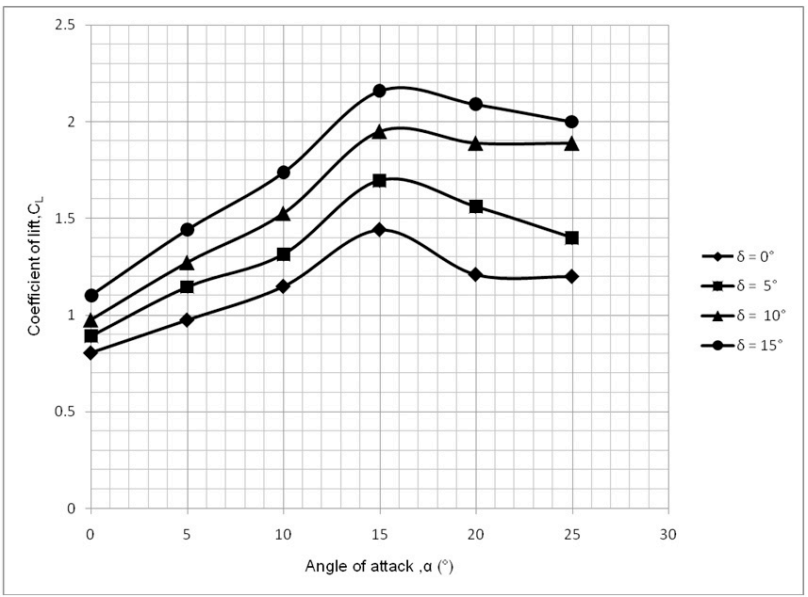

Fig. 11. Experimental variation of $C_{L}$ with angle of attack, $\alpha$ at different flap angle, $\delta$

When the SMA wire is actuated the flap deflects downward and this increases the active camber of the aerofoil structure. This increases the virtual angle of attack and hence the lift forces increases for the same angle of attack and wind velocity. The experimental lift coefficients were observed to be lower than that of the theoretical lift coefficients. This may be attributed to the vibration of the foil inside the wind tunnel.

\section{References}

1. Merja Sippola and Lindroos T., Adaptive Composite Structures in Shape Control Applications, Journal of Structural Mechanics, 40(1) (2007) 65-79.

2. Umesh K. and Ranjan Ganguly, Shape and Vibration Control of a Smart Composite Plate with Matrix Cracks, Journal of Smart Materials and Structures, 18 (2009) 13-20.

3. Yan $\mathrm{Ru} \mathrm{Hu}$ and George Vukovich, Active Robust Shape Control of Flexible Structures, Journal of Mechatronics, 15 (2005) 807820 .

4. Irschik H., A Review on Static and Dynamic Shape Control of Structures by Piezoelectric Actuation, Journal of Engineering Structures, 24 (2002) 5-11.

5. Seelecke S., and Muller I., Shape memory alloy actuators in smart structures: Modeling and simulation, Applied Mechanics Reviews, 57(1) (2004) 23-46.

6. Sup Choi and Jung Ju Lee, The Shape Control of Composite Beam with Embedded Shape Memory Alloy Wire Actuators", Journal of Smart Materials and Structures, 7 (1998) 759-770.

7. Kevin O'Toole, Mark McGrathn and Eugene Coyle, Analysis and Evaluation of the Dynamic Performance of SMA Actuators for Prosthetic Hand Design, Journal of Material Engineering and Performance, 18(56) (2009) 781-786.
8. Van Dam, C.P., The Aerodynamic Design of Multi-Element HighLift Systems for Transport Airplanes, Progress in Aerospace Sciences, 38 (2002) 101-144.

9. MacArthur M., Bio-inspired wing design to revolutionize aircraft flight, Canadian Aeronaut Space Inst, Toronto Flyer, 16(4) (2009) 6-7.

10. Shanghaun Kim and Maenghyo Cho., A Simple Smart Wing Actuator Using NiTi SMA, Journal of Mechanical Science and Technology, 9 (2010) 1865-1873.

11. Justin K.S. and Dimitris C.L., Khan M.A. and Yen J., Design and Implementation of a Shape Memory Alloy Actuated Reconfigurable Airfoil, J. Intelligent Material Systems and Strutures, 14 (2003) 257-273.

12. Sofla A.Y.N., Meguid S.A., Tan K.T., and Yeo W.K., Shape morphing of aircraft wing: Status and challenges, Materials and Design, 31 (2010) 1284-1292.

13. Clark H.M. and Waymen C. M., Surface relief effects in solid state phase transformation, Phase transformation, American Society of Metals, Chapman \& Hall Ltd., London, (1970) 59-114.

14. Kim S., and Cho M., Numerical simulation of double SMA wire actuator using two-way shape memory effect of SMA, Smart Mater. Struc., 16 (2007) 372-381. 
15. Vitiello, A., Giorleo, G., \& Morace, R. E., Analysis of thermomechanical behaviour of Nitinol wires with high strain rates, Smart Mater. Struct. 14 (2005) 215-221.

16. Wagner M., Sawaguchi T., Kausträter G., Höffken D., and Eggeler G., Structural fatigue of pseudoelastic NiTi shape memory wires. Mater. Sci. Eng. A, 378 (2004) 105-109.
17. Jacobs E.N., Ward K. E., and Pinkerton R.M., The characteristics of 78 related Airfoil sections from tests in the variable-density wind tunnel, NACA Report No. 460, 1933. 